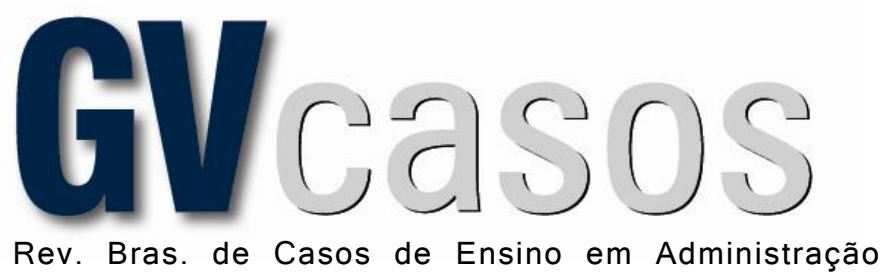

DOI: http://dx.doi.org/10.12660/gvcasosv11n2c14

\title{
CLIINICA DE EXAMES IRAPUÁ E OS DILEMAS DA ESTRATÉGIA
} Irapuá examinations clinic and the strategy dilemmas

Francisco Dias DuARTE - franciscodiasduarte @ icloud.com

Universidade do Vale do Rio dos Sinos - Porto Alegre, RS Brasil

KADíGIA FACCIN - kadigia@ gmail.com

Universidade do Vale do Rio dos Sinos - Porto Alegre, RS Brasil

LUCIANA MAINES Da SILVA - lucmasi@gmail.com

Universidade do Vale do Rio dos Sinos - Porto Alegre, RS Brasil

Submissão: 07/01/2021 | Aprovação: 04/06/2021

\section{Resumo}

Uma empresa do setor de Saúde (Medicina Diagnóstica) enfrenta a desaceleração de seus indicadores financeiros e se depara com a crise gerada pelo novo coronavírus. O objetivo do caso é mostrar aos alunos a importância de analisar diferentes perspectivas estratégicas relacionadas ao modelo de negócio e ao mercado no qual ele está inserido.

Palavras-chave: Estratégia empresarial, gestão em saúde, empresa familiar.

\section{Abstract}

A healthcare business (medical diagnostics) deals with the slowdown of its financial indicators and faces the new coronavirus crises. The case purpose is to show students the importance of analyzing different strategic perspectives regarding the business model and the market.

Keywords: business strategy, healthcare management, family business.

\section{Introdução}

2020, primeiro ano da pandemia, teve efeito marcante na situação econômica da Clínica de Exames Irapuá, decorrente da crise oriunda do novo coronavírus. Houve queda generalizada pela procura dos serviços médicos ambulatoriais, tanto em consultas como em exames e procedimentos eletivos em clínicas. O cenário era de retração econômica prevista na ordem de 5\% no Brasil. Como reflexo da necessidade do isolamento e posterior distanciamento social, a população postergou cuidados com a saúde que eram de rotina. $\mathrm{O}$ faturamento em geral do segmento foi reduzido em mais de 50\% com a queda de demanda, como foi caso da Irapuá. A clínica deparou-se com a necessidade de fazer demissões no quadro de pessoal técnico, médico, atendimento e administrativo, além de reduzir contratos com fornecedores. Para o Diretor Executivo Bento Athayde, era imprescindível que a empresa traçasse um plano estratégico para manter a sustentabilidade e viabilidade do negócio. Mesmo sem consenso sobre as melhores escolhas, demais sócios concordavam com a necessidade da tomada de decisão, enquanto o contexto ainda permitia.

\section{A empresa}

A Clínica de Exames Irapuá foi uma das pioneiras em oferecer exames de radiologia e diagnóstico por imagem fora do ambiente hospitalar, nos anos 1960, na capital gaúcha. Na época, os fundadores, Marcelo, Gustavo, Reginaldo, e seu o irmão mais novo, Tadeu, tiveram o instinto 
empreendedor que incentivou uma série de serviços concorrentes nos anos seguintes. A tecnologia era limitada aos aparelhos de raios $\mathrm{x}$ analógicos que realizam, além dos exames simples, os com meios de contraste na radiologia intervencionista.

Nos anos 1970 e 1980, manteve-se na vanguarda com o surgimento dos exames (e aparelhos) de ecografia/ultrassonografia, além de receber o primeiro equipamento de tomografia computadorizado do sul do Brasil, conforme anunciado no principal jornal da cidade. Na tecnologia mais avançada existente, a ressonância magnética, foi a primeira clínica a oferecer o serviço. Mais tarde, já em 2015, também liderou com a oferta da ressonância de ultra-alto campo 3T, que gerava imagens de altíssima resolução.

A partir dos anos 1990, a empresa ficou apenas com dois dos fundadores ativos na operação e na sociedade, Reginaldo e Tadeu, depois de adquirirem amigavelmente a participação dos espólios dos sócios falecidos. No final da mesma década, ainda iniciou um processo de profissionalização com a ajuda de consultoria externa especializada em gestão em saúde de empresas familiares. $\mathrm{O}$ resultado foi a contratação de um executivo externo assumindo a gestão do negócio.

Desde os anos 2000, a empresa teve crescimento anual entre $5 \%$ e $10 \%$, atingindo o pico de R\$ 13,7 milhões em 2019, desempenho que ainda não permitia uma política de dividendos, pois todo o recurso era consumido como capital de giro. Observa-se que o auge da receita ocorreu em 2016, com o valor de R\$15 milhões. Nos últimos anos, conseguiu manter o parque instalado atualizado, com geração de caixa e cultivando sua boa reputação de pioneirismo e qualidade. Cerca de 10 anos depois (2010), ocorreu uma reestruturação societária, ficando o negócio nas mãos dos fundadores e dos três filhos de Reginaldo, Cadu, Henrique e Bento. Os filhos de Tadeu tinham projetos distintos sem relação com a saúde, ficando apenas como herdeiros da empresa.

Reginaldo e Tadeu eram médicos, nascidos em Tupanciretã (RS), na faixa dos 80 anos. Vieram para a capital fazer faculdade e residência. Trabalharam em hospitais antes de empreender. Cadu, o primogênito, e Henrique seguiram a profissão do pai e fizeram carreira na Irapuá, o que não foi um impeditivo para se desenvolverem profissionalmente e adquirirem todos os títulos e habilitações necessárias para o exercício da especialidade. Bento, o caçula, apesar da forte influência familiar, optou por estudar Administração de Empresas, em especial, por gostar muito de marketing e negócios em geral. Além da graduação, fez especializações e mestrado. Os irmãos tinham 45, 40 e 30 anos respectivamente, todos casados e com um filho.

Com a sociedade renovada nas mãos da família, foram implementados processos de governança corporativa. Houve uma formalização do que já havia na prática: Reginaldo e Tadeu ficaram como Presidente e Vice-Presidente, Bento, como Diretor Administrativo e Henrique, como Diretor Médico. Cadu tinha perfil mais operacional e estava confortável com o cargo de Médico Sênior. Já ocorriam reuniões periódicas para prestação de contas da gestão, reuniões de acompanhamento do corpo clínico e auditoria contábil. Não foi criado Conselho de Administração, mas, para trazer uma dinâmica ainda mais profissional, uma vez por mês eram convidados consultores para reuniões ordinárias, proporcionando um olhar externo.

Nas últimas duas décadas, a Clínica investiu em ações de comunicação (propaganda) para divulgação de seus serviços e valorização de suas publicações científicas, muitas vezes premiadas em congressos e jornadas da especialidade radiológica. Percebia-se uma certa dependência dessa estratégia, pois se gastava com essas ações cerca de 5\% do faturamento, percentual considerado elevado no mercado.

A partir de 2017, mesmo com a operação indo relativamente bem, Bento começou a trazer para a mesa sua preocupação com o futuro do negócio, em virtude da ameaça de novos entrantes e do fortalecimento dos players atuais. O que tirava seu sono é como continuaria crescendo de maneira superavitária, uma vez que era muito difícil reajustar preço com os convênios, que representavam 90\% da receita, com custos crescendo anualmente, entre eles a folha de pagamento (convenção 
coletiva), pressão dos médicos por aumento de honorários e contratos de manutenção das máquinas em dólar.

No mesmo período em que houve crescimento até 2016, houve acompanhamento relativo do EBITDA, que ainda estava na média dos serviços de Medicina Diagnóstica. Por outro lado, mesmo sob controle, o endividamento vinha crescendo, em decorrência da necessidade de investimento permanentemente em tecnologia, instalações, pessoas e processos, deixando, assim, o resultado final positivo, mas irrisório. A empresa já estava no seu limite da alavancagem financeira, com perfil de dívida na ordem de R\$10 milhões, distribuída no curto, médio e longo prazos. Ademais, para novos empréstimos, seria necessário o aval dos sócios. Da mesma forma que dependiam do negócio como a única fonte de renda, ficavam inseguros em fazer novas captações, preocupados com o risco de insolvência também na pessoa física. Abaixo, o resumo das principais rubricas financeiras nos últimos nove anos, em milhões (R\$).

Tabela 1. Indicadores financeiros da empresa

\begin{tabular}{|l|l|l|l|l|l|l|l|l|l|}
\hline & 2011 & 2012 & 2013 & 2014 & 2015 & 2016 & 2017 & 2018 & 2019 \\
\hline Faturamento & 10,5 & 11,9 & 12,8 & 13,1 & 14 & 15 & 14,7 & 14,2 & 13,7 \\
\hline EBITDA & 1,57 & 2,1 & 2,5 & 3,1 & 3,9 & 3,7 & 3,2 & 2,7 & 3,0 \\
\hline Lucro & 0,525 & 0,36 & 0,450 & 0,390 & 0,280 & 0,270 & 0,310 & 0,200 & 0,150 \\
\hline Endividamento & 6,5 & 7,2 & 8,0 & 8,6 & 9,4 & 9,9 & 9,3 & 9,5 & 10,1 \\
\hline
\end{tabular}

Quanto à estrutura, a Irapuá operava em instalações de $3.000 \mathrm{~m} 2$ no mesmo local (sede única), e com cerca de 100 colaboradores, entre eles 30 Médicos Radiologistas (remuneração como pessoa jurídica - PJ), 20 Tecnólogos em Radiologia e o restante dividido entre os setores administrativo, atendimento e call center. Em 2020, o portfólio de exames era o seguinte:

- Ressonância magnética - Siemens3T e 1.5T;

- Tomografia computadorizada - GE 64C;

- Ultrassonografia/Ecografia - Toshiba, 10 aparelhos;

- Mamografia digital - Hologic, 2 aparelhos;

- Radiologia digital - Siemens;

- Densitometria óssea-GE.

\section{O mercado}

O mercado brasileiro de Medicina Diagnóstica vinha passando por um acentuado processo de consolidação entre os serviços existentes, em especial com transações que envolvem M\&A (sigla em inglês para fusões \& aquisições). Desde 2000, praticamente não existiam mais clínicas exclusivas de radiologia nas grandes capitais, mas sim serviços que incluem análises clínicas, "exames de sangue" e afins, sendo, assim, uma tendência evidente para ganhos de escalas mediante margem operacional unitária baixa. Nesse sentido, as marcas também buscaram aumentar sua capilaridade geográfica com filiais, ampliando e facilitando o acesso para os clientes, estratégia, por sinal, seguida pelo maior concorrente local da Irapuá.

A concorrência, inclusive, era considerada forte localmente, pois, além das clínicas, os hospitais atraíam parcela expressiva do mercado com os exames ambulatoriais, não somente os dos pacientes internados. Ademais, possuíam uma vantagem competitiva exclusiva, o corpo clínico engajado no direcionamento dos exames para o serviço de radiologia interno. Também surgiram com força os serviços verticalizados, realidade presente em todo o País, entre eles a Cooperativa Meduni 
e a empresa de Medicina de grupo Centro Sul, ambos com serviços próprios, que são a prioridade na hora do encaminhamento médico, sempre que a modalidade do plano permitir.

Analisando o poder de barganha do setor, o prestador de serviço médico encontrava desafios de todos os lados. Os convênios (fontes pagadoras como os planos de saúde, seguradoras, cooperativas e medicina de grupo) exerciam força para redução de preços, mesmo com orientação da Agência Nacional de Saúde (ANS) para o contrário. Os fornecedores de equipamentos, que eram poucos, ofereciam pequena diferença de preço, sendo atrelado ao dólar.

\section{O dilema}

Importante ressaltar que, antes da crise de 2020, já havia ameaças que preocupavam os sócios, como a dificuldade de crescimento e o poder de barganha de clientes e fornecedores. Ou seja, como a Clínica de Exames Irapuá permaneceria competitiva no mercado mediante queda abrupta na receita e tendo pela frente uma recuperação econômica lenta? Tendo já feito seu "tema de casa" com redução de custos, além de boas práticas de gestão para aumento da receita, seu dilema é: Qual o caminho estratégico mais adequado a seguir?

\section{Caminhos estratégicos}

Mesmo com a dificuldade de consenso para a escolha, todos concordavam que era necessário traçar um plano estratégico, mitigando riscos e vislumbrando os melhores resultados para o negócio.

Após uma série de reuniões durante a pandemia, os sócios, com a ajuda de alguns consultores de confiança, conseguiram identificar quatro estratégias possíveis:

1. Resiliência - contemplava seguir sozinhos, priorizando a manutenção da sociedade e modelo de negócio atuais.

Era a alternativa preferida por Reginaldo, afinal, além de ser fundador, tinha três filhos no negócio. Ou seja, era um entusiasta do "sonho" da empresa familiar. Cadu acompanhava o pai, pois tinha um perfil mais conservador e acreditava muito no modelo atual, além de não se sentir ameaçado pela concorrência ou pelas dívidas.

2. M\&A - contratação de assessoria especializada em operações de fusão e aquisição, partindo da premissa que, de alguma forma, o status quo fosse alterado com possibilidade de perda de controle por parte da família/sociedade atual.

Esse era o caminho defendido por Bento, pois analisava com preocupação os números e as tendências de mercado. O tio Tadeu acompanhava Bento, pois sua maior preocupação era monetizar suas cotas para deixar para a família. Henrique estava inclinado para M\&A, pois sabia que havia sido o desfecho da maioria das clínicas nos grandes centros, com a exceção dos que fecharam.

3. Ousadia - alavancagem financeira com a captação de mais empréstimos, aumentando o endividamento, apostando na contínua renovação do parque, branding e filiais.

Cadu parecia estar sozinho nesta opção, pois seus pares já não estavam mais confortáveis em pegar novas linhas de crédito.

4. Híbrida - estudar uma composição com as três alternativas anteriores, mantendo a continuidade do negócio no curto prazo, de modo a que se obtenha mais tempo para tomadas de decisão conclusivas com o desenvolvimento de um plano estratégico e sucessório.

Todos estavam abertos a esta alternativa, que ainda precisaria ser alinhada.

Como o futuro da empresa era um assunto delicado e complexo, sem "certo ou errado", Bento sugeriu um encontro do estilo seminário em um sábado de manhã, em ambiente externo, de modo que se pudesse respirar outros ares e que as tensões fossem atenuadas. Escolheu a Fazenda 
Silvestre, que oferece estrutura adequada para reuniões, além de permitir refeições ao ar livre, com preços justos.

Bento abriu o dia dando as boas-vindas aos sócios familiares, com o seguinte discurso: "Bom-dia, pessoal, obrigado por terem aceito o convite para tentarmos construir o melhor caminho para a Irapuá e nossas famílias. Seguimos bem-posicionados no mercado, mas vejo que nosso modelo esgotou. Para crescer, precisaremos de mais empréstimos cujo garantidores somos nós mesmos, o que é muito arriscado. Defendo a contratação da consultoria de M\&A para sentirmos a aceitação do mercado, e só iremos avançar se for bom para todos".

Cadu, um pouco nervoso rebateu: "Eu ainda acredito no nosso modelo, porque se estivermos unidos conseguiremos melhorar os resultados, nos mantendo enxutos e sem necessariamente pegar mais empréstimos".

O pai, Reginaldo, parecia não entender o cenário com M\&A: "Afinal, por que cogitamos vender a empresa? Temos uma clientela consolidada há mais de 50 anos... Quando fundamos o negócio, a situação era muito mais desafiadora".

O irmão, Tadeu, fez um contraponto: "Concordo, Reginaldo, mas não geramos resultado. Se viermos a faltar, como indenizaremos meus herdeiros?".

Por último, falou Henrique: "Precisamos buscar consenso. Claro que existe uma carga emocional aqui, mas precisamos ser racionais. Precisamos descobrir alternativas além de nós cinco, temos uma limitação de capital". 